\title{
Presentación de caso: Angina de Ludwig
}

\author{
Nieto Rizo JB. ${ }^{1}$, Maldonado Martínez bm. ${ }^{1}$
}

1 imss hgr ignacio García Tellez, Merida Yucatan, México.

La angina de Ludwig (AL) es potencialmente letal, es una celulitis que se esparce rápidamente por el piso de la boca y del cuello, con tendencia a causar edema, distorsión y obstrucción de la vía aérea(VA), que en consecuencia produce contratiempos en el abordaje de la vía aérea. Presentamos un caso de angina de Ludwig en una paciente de 73 años.

Presentación del caso: Femenino de 73 años, con el diagnóstico (AL) programado de manera urgente para drenaje de absceso localizado en área submandibular y submaxilar con extensión a cuello y hombro derecho. Inicia padecimiento actual hace aproximadamente tres semanas presentando dolor cervical y aumento de volumen progresivo en cuello, además de dificultad respiratoria.

Antecedentes personales patológicos: Obesidad grado I, Diabetes Mellitus tipo 2.

(VA) apertura oral I, Mallampati III, presencia de material purulento en orofaringe. Patil-Aldreti III, DEM de II, presencia de eritema y edema a nivel cervical, doloroso a la palpación y con aumento de la temperatura, induración a nivel submandibular y submaxilar con extensión a hombro derecho.

Plan A Intubación despierto con fibroscopio más sedación consciente con dexmedetomidina.

Plan B secuencia de intubación rápida con laringoscopia directa, utilizando rocuronio y sugammadex para revertirlo, si existe imposibilidad de ventilación o intubación.

Plan C traqueostomía de urgencia en caso de pérdida de la vía aérea.

Transanestesico: Se inicia Plan A. Se administra dexmedetomidina en infusión a $1 \mu \mathrm{g} / \mathrm{kg}$ durante diez minutos con mantenimiento a $0,2 \mu \mathrm{g} / \mathrm{kg} /$ hora. Se utiliza fibroscopio, se instila VA con lidocaína, fibroscopia imposible por secreciones, se aspiran y se realizan tres intentos sin éxito. Se inicia plan B. Se administra rocuronio $80 \mathrm{mg}$, fentanilo 150 $\mu \mathrm{g}$, propofol $100 \mathrm{mg}$ y se realiza laringoscopia, visualizando Cormack II. Se introduce TOT \#7 al primer intento.

Conclusiones: La AL es una patología potencialmente letal, en la cual se tiene que contar con un plan de manejo de la VA, así como planes alternativos debido a la variedad de presentaciones clínicas, las características de cada paciente en cuanto a su anatomía y comorbilidades, es por ello que el plan de manejo de VA debe individualizarse. Se tiene que enfatizar el diagnóstico temprano y el manejo oportuno ya que harán que el abordaje de la VA sea más sencillo.

https://doi.org/10.25237/congresoclasa2019.21 